\title{
Critical Analysis of an e-Learning and Interactive Teaching Module with Respect to the Interpretation of Emergency Computed Tomography of the Brain
}

\author{
Kritische Analyse eines e-Learning Moduls und \\ interaktiven Seminars zur Interpretation von \\ Notfall-Computertomografien des Gehirns
}

Authors

Michael Groth', Käthe Greta Barthe ${ }^{1}$, Martin Riemer², Marielle Ernst' ${ }^{1}$, Jochen Herrmann ${ }^{3}$, Jens Fiehler ${ }^{1}$, Jan-Hendrik Buhk ${ }^{1}$

Affiliations

1 Department of Diagnostic and Interventional Neuroradiology, University Medical Center Hamburg-Eppendorf, Hamburg, Germany

2 Department of Computational Neuroscience, University Medical Center Hamburg-Eppendorf, Hamburg, Germany

3 Department of Diagnostic and Interventional Radiology, Section of Pediatric Radiology, Universitätsklinikum Hamburg-Eppendorf, Hamburg, Germany

Key words

$\mathrm{CT}$, emergency, e-learning, neuroradiology, student

received 23.07.2017

accepted 29.11.2017

Bibliography

DOI https://doi.org/10.1055/s-0043-124191

Published online: 1.2.2018

Fortschr Röntgenstr 2018; 190: 334-340

(c) Georg Thieme Verlag KG, Stuttgart · New York ISSN 1438-9029

Correspondence

Dr. Michael Groth

Department of Diagnostic and Interventional Radiology,

University Medical Center Hamburg-Eppendorf,

Martinistr. 52, 20246 Hamburg, Germany

Tel.: ++ 49/40/428034029

Fax: ++49/40/428033802

groth.michael@googlemail.com

\section{ZUSAMMENFASSUNG}

Ziel Vergleich von drei verschiedenen Lehrmethoden zur Interpretation von Notfall-Pathologien mit der zerebralen Computertomografie (CT) durch Medizinstudenten.

Material und Methoden Drei Studentengruppen wurden bzgl. der Detektion von sieben CT-Pathologien getestet, nachdem sie verschiedene Lehrmethoden absolviert hatten (e-Learning, interaktives Seminar, curriculäre Lehre). Die Tes- tergebnisse der drei Gruppen wurde für jede Pathologie mit einem Chi-Quadrat-Test verglichen. Das Signifikanzniveau wurde $\leq 0,05$ gewählt.

Ergebnisse Im Gegensatz zur Vergleichsgruppe (curriculäre Lehre) zeigten die e-Learning- und Interaktivseminar-Gruppe signifikant bessere Ergebnisse bei der Detektion des „hyperdensen Mediazeichens" ( $p=0,001$ und $p<0,0001)$ sowie der Subarachnoidalblutung $(p=0,03$ und $p=0,001)$. Darüber hinaus zeigten sowohl die Interaktivseminar- als auch die e-Learning-Gruppe bessere Ergebnisse für die Detektion eines subduralen Hämatoms und einer Kalottenfraktur, wobei nur die letzte Gruppe hier eine statistische Signifikanz aufwies $(p=0,03$ und $p<0,0001)$. Keine signifikanten Unterschiede zeigten sich für Pathologien wie intrakranielle Blutung, epidurales Hämatom und Mittellinienverlagerung.

Zusammenfassung Unsere Studie zeigt jeweils unterschiedliche potentielle Vorteile der Interaktivseminar- sowie der e-Learning-Gruppe bei der Interpretation von CTs. Daher können interaktive Lehrmethoden das Potenzial besitzen, die studentisch-radiologische Ausbildung zu verbessern, die passende Lehrform muss jedoch dem jeweiligen Lerninhalt angepasst werden.

\section{Kernaussagen}

- E-Learning kann die studentische Beurteilungfähigkeit zerebraler CTs verbessern

- Ein interaktives Seminar kann die studentische Beurteilungfähigkeit zerebraler CTs verbessern

- E-Learning und Interaktivseminare besitzen unterschiedliche Stärken in der studentischen Radiologieausbildung

- Die Anwendung neuer Lehrmethoden in der Radiologie erfordert eine Lerninhalt spezifisch Anpassung

\section{ABSTRACT}

Purpose To compare the learning benefit of three different teaching strategies on the interpretation of emergency cerebral computed tomography (CT) pathologies by medical students.

Materials and Methods Three groups of students with different types of teaching (e-learning, interactive teaching, 
and standard curricular education in neuroradiology) were tested with respect to the detection of seven CT pathologies. The test results of each group were compared for each $C T$ pathology using the chi-square test. A p-value $\leq 0.05$ was considered to be significant.

Results Opposed to the results of the comparison group (curricular education), the e-learning group and interactive teaching tutorial group both showed a significantly better performance in detecting hyperdense middle cerebral artery sign $(p=0.001$ and $p<0.0001)$ as well as subarachnoid hemorrhage $(p=0.03$ and $p=0.001)$ on $C T$. Moreover, an increase in performance for the detection of subdural hematoma and skull fracture could be observed for both the interactive teaching group and the e-learning group, with statistical significance in the latter $(p=0.03$ and $p<0.0001$, respectively). No statistically significant differences were found for the detection of intracranial and epidural hemorrhage, as well as midline shift, among the groups studied.

Conclusion Our study demonstrates potential learning benefits for both the interactive teaching tutorial and e-learning module group with respect to reading CT scans with slightly different advantages. Thus, the introduction of new learning methods in radiological education might be reasonable at an undergraduate stage but requires learning content-based considerations.

\section{Key points}

- E-learning can offer benefits regarding the reading of cerebral CT scans by students

- Interactive tutorial can offer benefits regarding the reading of cerebral CT scans by students

- E-learning and interactive tutorial feature different strengths for student learning in radiology

- Application of interactive teaching methods in radiology requires learning content-based considerations

\section{Citation Format}

- Groth M, Barthe KG, Riemer M et al. Critical Analysis of an e-Learning and Interactive Teaching Module with Respect to the Interpretation of Emergency Computed Tomography of the Brain. Fortschr Röntgenstr 2018; 190: 334340

\section{Introduction}

Besides classic teacher-based lectures, the broad availability of computer technologies and the internet have led to increased implementation of e-learning, and especially case-based e-learning modules in medical education [1, 2]. This trend also affects education in radiology, which is known to be under-represented in many medical curricula [3]. Thus, e-learning might offer the potential to close this deficiency gap. Until recently, e-learning benefits could be shown for different radiology skills, like breast imaging [4, 5], chest X-ray interpretation [6], and ultrasound [7]. However, e-learning does not seem to always be superior to classic methods of teaching, like lectures and tutorials [8].

Therefore, the aim of this study was to compare the learning benefit in the interpretation of different emergency pathologies with cerebral computed tomography (CT) by medical students, who completed an e-learning module or interactive teaching tutorial complementary to their regular curricular education in neuroradiology.

\section{Materials and methods}

\section{Study population}

Three different student groups were tested in emergency CT:

- e-learning group: 38 students (24.9+- 5.6 years; 15 females and 23 males)

- interactive teaching group: 29 students (25.2 +- 3.7 years; 19 females and 10 males)

- control group: 33 students (24.4+- 3.1 years; 15 females and 17 males)
Between May and November 2014, students attended on a voluntary basis after invitation to participate. Qualification to participate was a successfully completed curricular education in neuroradiology at our university medical school no longer than two study semesters ago. The e-learning group attended an additional e-learning module and the interactive teaching group attended an additional teaching tutorial. Both the learning methods and the curricular medical education in neuroradiology are described in detail in the following paragraphs.

Participation was anonymous to ensure that test results could not constitute part of the formal assessment of the attending students. Moreover, all study observers were not involved in the curricular grading of the attending students. The study was approved by the local ethics committee (Ärztekammer Hamburg, WF-066/13).

\section{Curricular medical education in neuroradiology}

All participating students were enrolled at German University Medical Center Hamburg-Eppendorf for medical studies. They were studying according to the university's medical curriculum "KliniCuM" ("Klinisches Curriculum Medizin"). For neuroradiological education, "KliniCuM" included two 45-minute lectures and one 135-minute seminar about diagnostic and interventional neuroradiology [9]. Moreover, a 90-minute bedside lesson with emphasis on ischemic stroke and subarachnoid hemorrhage was taught by neuroradiologists [10]. For home studies, students were able to view the online version of a textbook for neuroradiology [11].

\section{E-learning module}

A casebook for emergency CCT was compiled based on the commercially available e-learning platform CASUS [12]. The casebook included 13 CT cases and an introductory chapter, in which the 


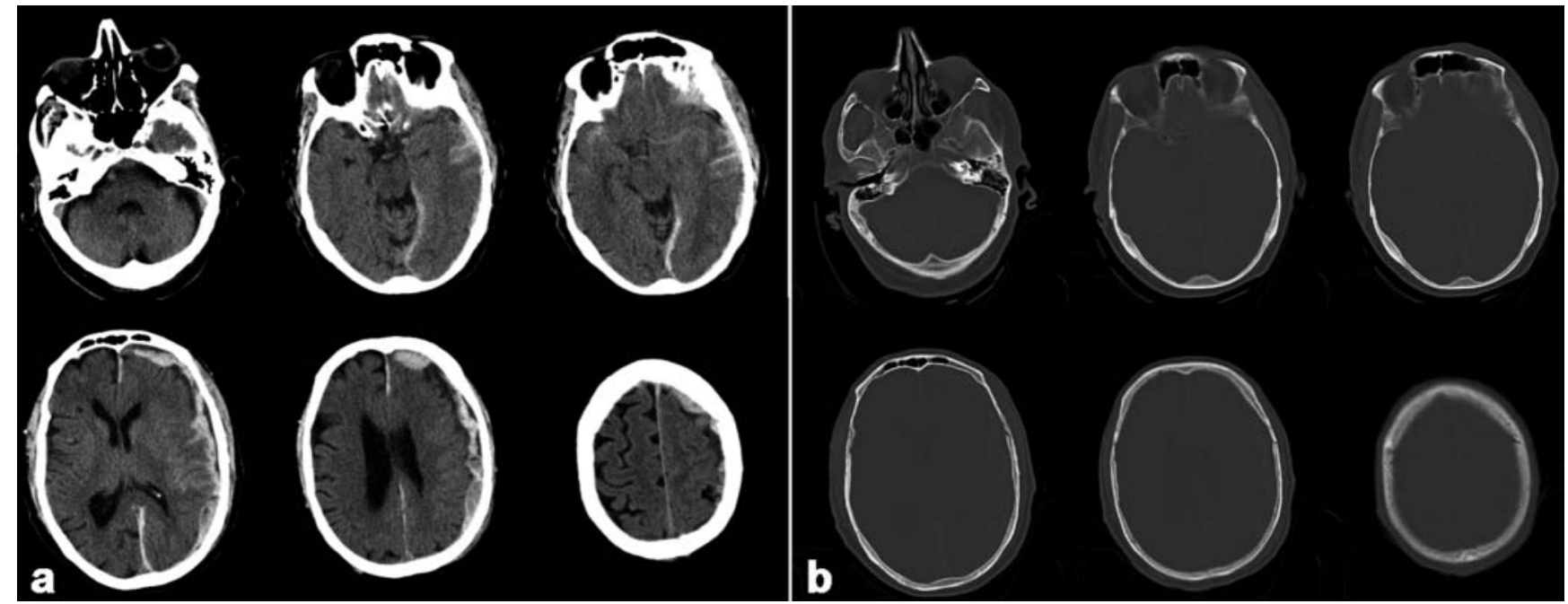

- Fig. 1 Presentation of an emergency CT case in the e-learning and interactive teaching tutorial group. Six exemplary slices of a CT dataset are shown in the "brain" a and "bone" b window. Pathologic findings in the "brain" window a are marked in Fig. 2.

- Abb. 1 Beispiel der Darstellungsform eines Notfall-CT Falles im e-Learning Modul und dem Interaktivseminar. Sechs exemplarische Schichten eines CT-Datensatzes sind sowohl im „Weichteil-“ als auch im „Knochenfenster“ dargestellt. Die Pathologien dieses Falles sind in Abb. 2 im „Weichteilfenster“ markiert.

students were taught the basics of emergency CT appraisal. The clear-cut cases were selected by two specialists in neuroradiology (M.G. and J.H.B.). For each case six CT slices were presented in the "brain window" and "bone window" ( $\triangleright$ Fig. 1). The casebook also included cases without any pathology. For each case the student was asked if the following pathologies were present: midline shift, epidural hematoma, subdural hematoma, subarachnoid hematoma, intracerebral hemorrhage, hyperdense middle cerebral artery sign, and skull fracture. Once a decision was made, the student was shown the right answers and additional case-based information. Furthermore, pathologies were marked on an answer slice ( $\vee$ Fig. 2).

\section{Interactive teaching tutorial}

The interactive teaching tutorial was a 90-minute tutorial, which included the same cases and introductory chapter as the CASUS e-learning module. In contrast to the e-learning module, the cases were presented using a projector by a tutor. The tutor was not involved in curricular grading of the attending students and was not aware of the test cases mentioned below at the time of presentation to avoid observer-expectancy bias. In dependence on the e-learning module, the tutor asked the students for each case if the following pathologies were present: midline shift, epidural hematoma, subdural hematoma, subarachnoid hematoma, intracerebral hemorrhage, hyperdense middle cerebral artery sign, and skull fracture. In contrast to the e-learning module, the students had the possibility to ask questions and discuss with the tutor whenever they wanted.

\section{Test}

The test included nine clear-cut CT cases with different CT findings ( $\triangleright$ Table $\mathbf{1}$ ). The cases were selected by two specialists in

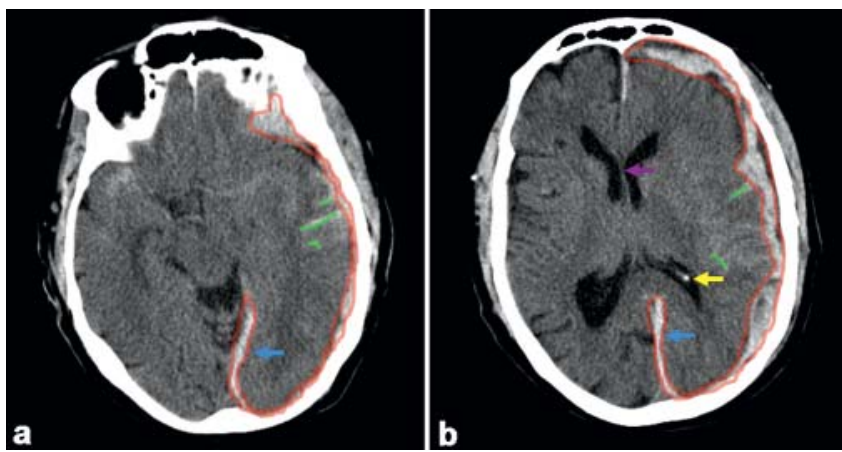

Fig. 2 e-learning module answer slices for the same case presented in $>$ Fig. 1 Pathological findings include subarachnoid hemorrhage (marked green in a, b), midline shift to the right (purple arrow in $\mathbf{b}$ ), and left-sided subdural hematoma (marked red in a, b), which extends along cerebral falx (blue arrow in a, b). Physiologic calcification of the left choroid plexus is also marked (yellow arrow in $\mathbf{b}$ ).

- Abb. 2 Antwortfolie des e-Learning Moduls für den in $>$ Abb. 1 dargestellten CT-Fall. Folgende Pathologien sind markiert: Subarachnoidalblutung (grün in a, b), Mittellinienverlagerung (lila in b), linksseitiges Subduralhämatom (rot in a, b), welches sich entlang der Falc cerebri ausbreitet (blau in a, b). Physiologische Kalzifikationen des linken Plexus choroideus wurden gelb markiert.

neuroradiology (M.G. and J.H.B.). The time interval between completion of the e-learning module or interactive teaching module was one to two weeks, with all participating students having fulfilled their curricular education in neuroradiology in a period no longer than two study semesters ago.

\section{Questionnaire}

All students of the e-learning module group completed a questionnaire, which included five questions about e-learning. The 
- Table 1 Test cases with their respective CCT findings.

- Tab. 1 Testfälle mit ihren jeweiligen Pathologien.

\begin{tabular}{|c|c|c|c|c|c|c|c|}
\hline case no. & MS & EDH & SDH & SAH & ICH & HMS & SF \\
\hline 1 & $x$ & & $x$ & $x$ & & & \\
\hline 2 & & & & & & $x$ & \\
\hline \multicolumn{8}{|l|}{3} \\
\hline 4 & $x$ & $x$ & & & & & $X$ \\
\hline 5 & & $x$ & & & & & $x$ \\
\hline \multicolumn{8}{|l|}{6} \\
\hline 7 & $x$ & & $X$ & $x$ & $x$ & & $x$ \\
\hline 8 & $x$ & & & & $x$ & & \\
\hline 9 & & & & & & $X$ & \\
\hline
\end{tabular}

students were asked to score each question using a 6-point Likert scale.

\section{Statistical Analysis}

Statistical analysis was performed using Microsoft Excel 2003 (Microsoft, Seattle, USA) and SPSS11.5 (SPSS Inc., Chicago, USA). With the consensus read-out of two specialists in neuroradiology (M.G. and J.H.B.) serving as the standard of reference, the sensitivity, specificity, positive predictive value, and negative predictive value were calculated separately for the seven tested CT pathologies as well as for the three different student groups. Differences between the groups for each CT pathology were tested using chisquare test. A p-value of less than 0.05 was considered to be significant.

\section{Results}

\section{Comparison of different learning groups}

The sensitivity, specificity, PPV, and NPV in the reference to the control group for different $\mathrm{CT}$ findings in different groups are listed in $>$ Table 2. For subarachnoid hematoma and the hyperdense middle cerebral artery sign, both the e-learning and interactive teaching group showed significantly better performance than the comparison group ( $p=0.03$ and 0.001 as well as $p=0.001$ and $<0.0001$, respectively). Regarding the hyperdense middle cerebral artery sign, the interactive teaching group even performed significantly better than the e-learning group $(p=0.04)$. In contrast to the comparison group, significantly increased diagnostic skills could be observed for subdural hematoma $(p=0.03)$ and skull fracture $(p<0.0001)$ in the e-learning group, whereas the last one even showed significantly better performance than the interactive teaching group $(p=0.01)$. All $p$-values are listed in - Table 2.

\section{Questionnaire}

More than $95 \%$ of the students awarded a Likert score of 4 points or more regarding the following questions: whether the e-learning module is user-friendly as well as reasonable for medical education, whether the module expanded their knowledge of CT, and if they were interested in completing e-learning modules in other topics in radiology. Only 12 (32\%) students gave a Likert score of 4 or more, when asked if the e-learning module could replace tutorials. The complete results of the questionnaire completed by the e-learning group are listed in $>$ Table 3 .

\section{Discussion}

This study compares the learning benefit with regard to the interpretation of different emergency CT pathologies by medical students, who completed an e-learning module or interactive teaching tutorial complementary to their regular curricular education in neuroradiology. Both learning methods showed learning advantages, which were dependent on the different pathologies.

For example, the highest increase in sensitivity/specificity could be found for the detection of a hyperdense middle cerebral artery sign in the interactive teaching group with 95/98\% compared to $56 / 92 \%$ in the control group. This was even significantly better than the results of the e-learning group (76/98\%). Therefore, the detection of the hyperdense middle cerebral artery sign seems to be a skill, which benefits from additional teaching methods. However, since the selected test cases were clear-cut cases, the sensitivity and specificity would be expected to be lower for the same medical students in a real-world scenario. This is underlined by a recent study in which the diagnostic sensitivity/specificity was much lower (63\%/91\%) for the visual detection of the hyperdense middle cerebral media sign by radiologic physicians for consecutive cases without selection bias [13]. 
- Table 2 Sensitivity, specificity, positive predictive value, and negative predictive value in reference to control group and statistical differences between the different learning groups for different pathologies.

- Tab.2 Sensitivität, Spezifität, positiver und negativer prädiktiver Vorhersagewert in Referenz zur Kontrollgruppe sowie statistische Unterschiede der verschieden Lerngruppen bzgl. der verschiedenen Pathologien.

\begin{tabular}{|c|c|c|c|c|c|c|}
\hline & CP & EG & ITG & p-value (CP vs. EG) & p-value (CP vs. ITG) & p-value (EG vs. ITG) \\
\hline \multicolumn{7}{|c|}{ midline shift } \\
\hline sensitivity & $80(72-87)$ & $93(87-97)$ & $81(72-88)$ & \multirow[t]{4}{*}{0.79} & \multirow[t]{4}{*}{0.77} & \multirow[t]{4}{*}{0.95} \\
\hline specificity & $96(92-99)$ & $87(81-91)$ & $94(89-97)$ & & & \\
\hline PPV & $95(88-98)$ & $82(74-87)$ & $91(84-96)$ & & & \\
\hline NPV & $86(80-91)$ & $95(91-98)$ & $86(80-91)$ & & & \\
\hline \multicolumn{7}{|c|}{ epidural hematoma } \\
\hline sensitivity & $73(60-83)$ & $77(66-86)$ & $83(71-91)$ & \multirow[t]{4}{*}{0.47} & \multirow[t]{4}{*}{0.59} & \multirow[t]{4}{*}{0.35} \\
\hline specificity & $97(94-99)$ & $94(91-97)$ & $98(94-99)$ & & & \\
\hline PPV & $87(75-94)$ & $80(69-88)$ & $91(79-97)$ & & & \\
\hline NPV & $93(88-95)$ & $93(89-96)$ & $95(91-98)$ & & & \\
\hline \multicolumn{7}{|c|}{ subdural hematoma } \\
\hline sensitivity & $51(39-64)$ & $75(64-84)$ & $72(59-83)$ & \multirow[t]{4}{*}{0.03} & \multirow[t]{4}{*}{0.12} & \multirow[t]{4}{*}{0.97} \\
\hline specificity & $93(88-96)$ & $94(91-97)$ & $94(89-97)$ & & & \\
\hline PPV & $67(52-79)$ & $79(68-88)$ & $76(63-87)$ & & & \\
\hline NPV & $87(82-91)$ & $93(89-96)$ & $92(88-96)$ & & & \\
\hline \multicolumn{7}{|c|}{ subarachnoid hematoma } \\
\hline sensitivity & $61(48-72)$ & $82(71-89)$ & $91(81-97)$ & \multirow[t]{4}{*}{0.03} & \multirow[t]{4}{*}{0.001} & \multirow[t]{4}{*}{0.36} \\
\hline specificity & $92(88-95)$ & $90(85-93)$ & $92(87-95)$ & & & \\
\hline PPV & $69(55-80)$ & $69(58-78)$ & $76(64-85)$ & & & \\
\hline NPV & $89(84-93)$ & $94(91-97)$ & $97(94-99)$ & & & \\
\hline \multicolumn{7}{|c|}{ intracerebral hemorrhage } \\
\hline sensitivity & $89(79-95)$ & $95(86-98)$ & $97(88-99)$ & \multirow[t]{4}{*}{0.60} & \multirow[t]{4}{*}{0.45} & \multirow[t]{4}{*}{0.62} \\
\hline specificity & $94(90-97)$ & $93(89-96)$ & $96(92-98)$ & & & \\
\hline PPV & $82(71-90)$ & $79(69-87)$ & $86(75-93)$ & & & \\
\hline NPV & $97(93-99)$ & $98(96-99)$ & $99(96-99)$ & & & \\
\hline \multicolumn{7}{|c|}{ hyperdense media sign } \\
\hline sensitivity & $56(43-68)$ & $76(65-85)$ & $95(85-99)$ & \multirow[t]{4}{*}{0.001} & \multirow[t]{4}{*}{$<0.0001$} & \multirow[t]{4}{*}{0.04} \\
\hline specificity & $92(88-95)$ & $98(95-99)$ & $98(94-99)$ & & & \\
\hline PPV & $67(53-79)$ & $92(82-97)$ & $91(81-97)$ & & & \\
\hline NPV & $88(83-92)$ & $94(90-96)$ & $99(95-99)$ & & & \\
\hline \multicolumn{7}{|c|}{ skull fracture } \\
\hline sensitivity & $31(23-42)$ & $60(51-67)$ & $48(37-59)$ & \multirow[t]{4}{*}{$<0.0001$} & \multirow[t]{4}{*}{0.10} & \multirow[t]{4}{*}{0.01} \\
\hline specificity & $96(91-98)$ & $95(91-97)$ & $93(88-96)$ & & & \\
\hline PPV & $78(61-89)$ & $91(83-95)$ & $78(64-88)$ & & & \\
\hline NPV & $74(68-79)$ & $75(69-89)$ & $78(72-83)$ & & & \\
\hline
\end{tabular}

Control group (CG); e-learning group (EG); interactive teaching group (ITG); positive predictive value (PPV); negative predictive value (NPV). Values are listed in percent with their $95 \%$ confidence interval in brackets.

Another pathology for which a significant increase in sensitivity in the interactive teaching group ( $91 \%$ vs. $61 \%$ ) as well as the e-learning group ( $82 \%$ vs. $61 \%$, control group, respectively) could be found was subarachnoid hemorrhage. When scans are interpreted by a neuroradiologist or qualified general radiologist, 
- Table 3 Results of the questionnaire completed by the 38 students of the e-learning group (6-point Likert scale).

- Tab.3 Ergebnisse des von 38 Studenten der e-Learning-Gruppe ausgefüllten Fragebogens (6-Punkt Likert Skala).

\begin{tabular}{|c|c|c|c|c|c|c|}
\hline & strongly disagree & disagree & somewhat disagree & somewhat agree & agree & strongly agree \\
\hline $\begin{array}{l}\text { "ELM is reasonable for medical } \\
\text { education." }\end{array}$ & $\begin{array}{l}0 \\
(0 \%)\end{array}$ & $\begin{array}{l}0 \\
(0 \%)\end{array}$ & $\begin{array}{l}0 \\
(0 \%)\end{array}$ & $\begin{array}{l}1 \\
(3 \%)\end{array}$ & $\begin{array}{l}15 \\
(39 \%)\end{array}$ & $\begin{array}{l}22 \\
(58 \%)\end{array}$ \\
\hline $\begin{array}{l}\text { "ELM expanded my knowledge } \\
\text { of CCT." }\end{array}$ & $\begin{array}{l}0 \\
(0 \%)\end{array}$ & $\begin{array}{l}0 \\
(0 \%)\end{array}$ & $\begin{array}{l}0 \\
(0 \%)\end{array}$ & $\begin{array}{l}2 \\
(5 \%)\end{array}$ & $\begin{array}{l}19 \\
(50 \%)\end{array}$ & $\begin{array}{l}17 \\
(45 \%)\end{array}$ \\
\hline "ELM is able to replace tutorials." & $\begin{array}{l}2 \\
(5 \%)\end{array}$ & $\begin{array}{l}8 \\
(21 \%)\end{array}$ & $\begin{array}{l}16 \\
(42 \%)\end{array}$ & $\begin{array}{l}9 \\
(24 \%)\end{array}$ & $\begin{array}{l}1 \\
(3 \%)\end{array}$ & $\begin{array}{l}2 \\
(5 \%)\end{array}$ \\
\hline "ELM is user-friendly." & $\begin{array}{l}0 \\
(0 \%)\end{array}$ & $\begin{array}{l}0 \\
(0 \%)\end{array}$ & $\begin{array}{l}1 \\
(3 \%)\end{array}$ & $\begin{array}{l}4 \\
(11 \%)\end{array}$ & $\begin{array}{l}14 \\
(37 \%)\end{array}$ & $\begin{array}{l}19 \\
(50 \%)\end{array}$ \\
\hline $\begin{array}{l}\text { "I am interested in completing } \\
\text { ELM in other topics in radiology." }\end{array}$ & $\begin{array}{l}1 \\
(3 \%)\end{array}$ & $\begin{array}{l}0 \\
(0 \%)\end{array}$ & $\begin{array}{l}0 \\
(0 \%)\end{array}$ & $\begin{array}{l}4 \\
(11 \%)\end{array}$ & $\begin{array}{l}11 \\
(29 \%)\end{array}$ & $\begin{array}{l}22 \\
(58 \%)\end{array}$ \\
\hline
\end{tabular}

a sensitivity of up to $100 \%$ for the detection of subarachnoid hemorrhage is reported in other studies $[14,15]$.

An increase in sensitivity for subdural hematoma and skull fracture could be observed for both the interactive teaching group and the e-learning group, but only the e-learning group revealed a significant difference. Subdural hematomas $<3 \mathrm{~mm}$ are often difficult to detect on CT scans [16]. This might explain why extensive teaching results in higher sensitivity for detection. Skull fracture seems to be a pathologic $\mathrm{CT}$ finding that benefits from extensive teaching, too. Since skull fractures might present as a very subtle finding on a CT scan and differentiation from normal skull sutures could be difficult in some cases, a teaching-based improvement of sensitivity sounds feasible.

Intracerebral hemorrhages with a lesion size of $2 \mathrm{~cm}$ or more and epidural hematomas thicker than $5 \mathrm{~mm}$ can be detected by CT with very high sensitivity [16]. Since all cases of intracerebral hemorrhage and epidural hematoma that were included in the test were this size or larger, the lack of significant changes for this pathology is not surprising.

Moreover, no significant difference in the detection of a pathologic midline shift on a CT scan could be observed for the e-learning group as well as the interactive teaching group. Because of the symmetrical configuration of the normal brain, detection of an obvious asymmetric configuration, as it could be observed in our cases of midline shift, does not seem to require additional teaching.

The abovementioned results indicate that e-learning is capable of offering learning benefits for some but not all learning content. This is in accordance with the results of the questionnaire, which was completed by students of the e-learning module group. Most of the students answered that the e-learning module expanded their knowledge of $\mathrm{CT}$, but only $32 \%$ stated that the module alone could replace tutorials.

However, besides e-learning, interactive teaching seems to be useful for particular learning content, too. This is in line with recent studies, which evaluated the value of interactive teaching in student's education $[17,18]$. In a study that distributed ques- tionnaires to medical students, interactive case-based discussions were clearly preferred over conventional teaching methods [19].

Taking these observations together, it would be interesting to develop and evaluate new learning modules that combine e-learning and interactive teaching.

\section{Certain limitations of our study have to be addressed}

A major limitation of our study is that students of the e-learning group as well as the interactive teaching group received additional and focused training on CT pathologies that was relevant for the test. Students who only completed curricular education obtained broader knowledge and are expected to have invested less study time. However, our results showed that additional training in the e-learning or interactive teaching group did not significantly increase diagnostic skills for some pathologies like midline shift, epidural hematoma and intracerebral hemorrhage. Therefore, focused training with e-learning or interactive teaching does not seem to be reasonable for all learning content.

As mentioned above, students of the e-learning and interactive teaching group probably spend more time on neuroradiologic topics. Nevertheless, the exact overall learning time invested by the students of the different groups was not recorded, since especially time for self-study would have been very difficult to document.

Another limitation is that the time interval between the completion of the e-learning module or interactive teaching module and the test was very short at only $1-2$ weeks. Thus, no statement about the long-term learning effect can be made. Furthermore, a certain study bias could not be excluded, because the period of time during which the participating students fulfilled their curricular education in neuroradiology was up to two study semesters. It would have been desirable to include only students who had just finished their curricular education in neuroradiology. Indeed, acquisition of a large number of volunteers under this condition would be doubtful. 
Moreover, as most studies dealing with e-learning in radiology [20], the evaluation of our e-learning module is based on a questionnaire to score student satisfaction as well as a test after intervention. Therefore, no objective conclusion about a change in performance regarding clinical practice or patient outcome can be made. As mentioned before in the review by Zafar et al., this is a general problem in medical education studies, since this will always be difficult to evaluate [20].

Furthermore, the variability of intellectual skill and performance of participating students were not evaluated and might therefore have been inhomogeneous in the three different test groups. However, the fact that not all CT pathologies performed better in one group may indicate homogeneous intellectual skills between the different groups. Otherwise, one would expect one group to perform better for all CT pathologies.

Another limitation of our study is that only seven CT pathologies were evaluated. Some important pathologies like loss of grey-white matter differentiation caused by changes of radiolucency due to cytotoxic edema [21] were not part of the e-learning module and interactive teaching tutorial. However, because the target audience was medical students, it was not the goal to include all learning content of a neuroradiology fellowship. Nevertheless, since various training sessions are offered for attending neuroradiologists [22], it would be interesting to create an additional e-learning module and evaluate it against conventional teaching offerings in the future.

\section{Conclusion}

Our study demonstrates potential learning benefits with slightly different advantages for both the interactive teaching group and e-learning module group with respect to reading CT scans. Thus, introduction of new learning methods in radiological education might be reasonable at an undergraduate stage but requires learning content-based considerations.

\section{Conflict of Interest}

The authors declare that they have no conflict of interest.

\section{References}

[1] Howlett D, Vincent T, Watson G et al. Blending online techniques with traditional face to face teaching methods to deliver final year undergraduate radiology learning content. Eur J Radiol 2011; 78: 334-341

[2] Pinto A, Brunese L, Pinto $F$ et al. E-learning and education in radiology. Eur J Radiol 2011; 78: 368-371

[3] Wong V, Smith A], Hawkins N] et al. Adaptive Tutorials Versus WebBased Resources in Radiology: A Mixed Methods Comparison of Efficacy and Student Engagement. Acad Radiol 2015; 22: 1299-1307
[4] Moreira IC, Ventura SR, Ramos I et al. Development and assessment of an e-learning course on breast imaging for radiographers: a stratified randomized controlled trial. J Med Internet Res 2015; 17: e3

[5] Soh BP, Reed WM, Poulos A et al. E-tutorial improves students' ability to detect lesions. Radiol Technol 2013; 85: 17-26

[6] Salajegheh A, Jahangiri A, Dolan-Evans E et al. A combination of traditional learning and e-learning can be more effective on radiological interpretation skills in medical students: a pre- and post-intervention study. BMC Med Educ 2016; 16: 46

[7] Beaulieu Y, Laprise R, Drolet P et al. Bedside ultrasound training using web-based e-learning and simulation early in the curriculum of residents. Crit Ultrasound J 2015; 7: 1

[8] Guri-Rosenblit S. Eight paradoxes in the implementation process of e-learning in higher education. Distances et savoirs 2006; 4: 155-179

[9] Themenblockbuch VI KliniCuM. http://www.uke.de/dateien/einrichtungen/medizinische-fakultät/dokumente/tb6-_blockbuch-_-januar-bisapril-2016_endversion.pdf accessed 20 April 2016.

[10] Themenblockbuch IV KliniCuM. http://www.uke.de/dateien/einrichtungen/medizinische-fakultät/dokumente/themenblockbuch-4-_-april-bisjuli-2016.pdf accessed 20 April 2016.

[11] Linn J. Atlas Klinische Neuroradiologie des Gehirns. Berlin / Heidelberg / New York: Springer-Verlag; 2011

[12] http://hhu.casus.net/pmw2/app/homepage.html accessed 20 April 2016.

[13] Ernst M, Romero JM, Buhk JH et al. Sensitivity of visual and quantitative detection of middle cerebral artery occlusion on non-contrast-enhanced computed tomography. Neuroradiology 2014; 56: 1063-1068

[14] Perry J], Stiell IG, Sivilotti ML et al. Sensitivity of computed tomography performed within six hours of onset of headache for diagnosis of subarachnoid haemorrhage: prospective cohort study. BMJ 2011; 343: doi: d 4277

[15] Dubosh NM, Bellolio MF, Rabinstein AA et al. Sensitivity of Early Brain Computed Tomography to Exclude Aneurysmal Subarachnoid Hemorrhage: A Systematic Review and Meta-Analysis. Stroke 2016; 47: 750 - 755

[16] Gentry LR, Godersky JC, Thompson B et al. Prospective comparative study of intermediate-field MR and CT in the evaluation of closed head trauma. Am J Roentgenol 1988; 150: 673-682

[17] Datta R, Datta K, Venkatesh MD. Evaluation of interactive teaching for undergraduate medical students using a classroom interactive response system in India. Med J Armed Forces India 2015; 71: 239-245

[18] Abdel MeguidE, Collins M. Students' perceptions of lecturing approaches: traditional versus interactive teaching. Adv Med Educ Pract 2017; 8: $229-241$

[19] Nyhsen CM, Steinberg LJ, O’Connell JE. Undergraduate radiology teaching from the student's perspective. Insights Imaging 2013; 4: 103 - 109

[20] Zafar S, Safdar S, Zafar AN. Evaluation of use of e-Learning in undergraduate radiology education: a review. Eur J Radiol 2014; 83: 2277 2287

[21] Fiehler J, Fiebach JB, Gass A et al. Diffusion-weighted imaging in acute stroke-a tool of uncertain value? Cerebrovasc Dis 2002; 14: 187- 196

[22] Wiesmann M, Knauth M, Mayer T. Advanced and continuing education in neuroradiology. Clin Neuroradiol 2015; 25 (Suppl. 2): 127-128 